\title{
Extreme Behavioral Adjustments by an Orb-Web Spider to Restricted Spaces
}

\author{
Gilbert Barrantes* \& William G. Eberhard*† \\ * Escuela de Biología, Universidad de Costa Rica, Ciudad Universitaria Rodrigo Facio, San José, Costa Rica \\ $\uparrow$ Smithsonian Tropical Research Institute, Panama, USA
}

\author{
Correspondence \\ Gilbert Barrantes, Escuela de Biología, \\ Universidad de Costa Rica, Ciudad \\ Universitaria Rodrigo Facio, San José, \\ Costa Rica, CP 2060. \\ E-mail: gilbert.barrantes@gmail.com \\ Received: November 17, 2011 \\ Initial acceptance: January 2, 2012 \\ Final acceptance: January 19, 2012 \\ (D. Zeh)
}

doi: 10.1111/j.1439-0310.2012.02029.x

\begin{abstract}
Adaptive flexibility in response to environmental variation is often advantageous and occurs in many types of traits in many species. Although the basic designs of the orb webs of a given species are relatively uniform, spiders can adjust their webs to some types of environmental variation. This study of adult female Leucauge argyra tests the extremes to which they can adjust with respect to reduced area in which to build, and documents probably the most pronounced flexibility in orb design ever recorded. These adjustments revealed several behavioral rules that guide orb construction behavior. Spiders adjusted at least seven probably independent aspects of orb design when confined in tiny spaces that spanned about $7 \%$ of the maximum distance normally spanned by webs in the field and that had diameters that were only about three times the length of the spider itself. Webs in intermediate sized containers had intermediate designs, and many of the adjustments appear to result from extensions of the behavioral rules guiding orb construction in less severely restricted spaces in the field.
\end{abstract}

\section{Introduction}

Adaptive phenotypic flexibility occurs in many traits in many different organisms and has profound evolutionary consequences (West-Eberhard 2006). Spider orb-web construction behavior exemplifies complex, highly stereotyped, relatively innate behavior whose details can nevertheless be adjusted to some extent to local conditions (Witt et al. 1968; Vollrath 1992; Heiling \& Herberstein 2000), and the former perception of stereotypy in orb design is currently being replaced by the realization that details of orb design are extremely flexible (Herberstein $\delta$ Tso 2011). There is a long list of variables that are known to induce orb weavers to modify orb designs or that are at least correlated with differences in orb design. It includes the size and shape of the space available (LeGuelte 1966; Ades 1986; Leborgne \& Pasquet 1987; Krink \& Vollrath 2000; Harmer \& Herberstein 2009; Hesselberg 2010), closed vs. open habitats (Blamires et al. 2007), gravity (LeGuelte
1966; Vollrath 1992; Herberstein \& Heiling 1999), the amount of silk in the silk glands that spiders have to construct the web (Reed et al. 1970; Eberhard 1988a), the presence of other lines they have already built (Hingston 1920, 1922; Eberhard 1972; Gillespie 1987), previous overall foraging success (Higgins 1992; Vollrath 1992; Sherman 1994; Herberstein \& Heiling 1999; Herberstein et al. 2000) and also localized success in different parts of the web (Heiling \& Herberstein 2000), body weight (Herberstein \& Heiling 1999), impending molt or oviposisiton (Higgins 1990; Sherman 1994), recent memories of distances and directions they have moved (Eberhard 1988b; W. G. Eberhard \& T. Hesselberg, submitted), weather conditions and previous rainfall (and thus damage to the previous web) (Cangialosi \& Uetz 1987; Higgins \& Buskirk 1992), predation risk (Higgins 1992), and to the type of prey available (Sandoval 1994). Orb weaving spiders may be unusual among invertebrates in that they take into account unusually large numbers of stimuli in 
making some decisions: For instance, each of the 1000 or more decisions regarding where to attach the sticky spiral to a radius during the construction of a single orb can be affected by up to eight different stimuli (W. G. Eberhard \& T. Hesselberg, submitted).

The sizes and shapes of the spaces in nature in which a spider can build an orb vary widely (Witt 1965; Ades 1986; Vollrath 1992). Previous studies showed that the araneids Zygiella x-notata, Araneus diadematus, Argiope argentata and Telaprocera maudae, and the nephilid Nephila clavipes modified the shapes of their orbs substantially to conform to the shape of the area defined by the supports near the spider's retreat and the walls of the container in which the spider was housed (LeGuelte 1966; Ades 1986; Krink \& Vollrath 2000; Harmer \& Herberstein 2009; Hesselberg 2010). By presenting spiders with extreme sizes and shapes of spaces in which to build, it is possible to elucidate the cues they use to guide their construction behavior. For instance, by offering A. diadematus long, narrow spaces in which to build, Krink \& Vollrath (2000) induced them to build long, narrow orbs; the highly reduced spaces between sticky spiral loops on the short, horizontal radii compared with the larger spaces on longer radii above and below the hub suggested that some cue related to radius length affects decisions where to attach sticky spiral loops. Experimental manipulations allow one to document otherwise weak trends by extending the range of variation, and also offer ways to overcome the common problem in orb-web studies that some correlations among different variables may be due to the geometric regularity of the web rather than to cause and effect. The spider's ability to adjust to spatial limitations and the limits within which it is capable of making adjustments are traits in and of themselves and have the potential to be informative regarding taxonomic relationships (W. G. Eberhard \& G. Barrantes, in prep.).

This study of the tetragnathid Leucauge argyra tests the extremes to which spiders can adapt their orb webs to sites with reduced areas, the degree of flexibility of the designs of orbs build in spaces with different sizes, and the possible stimuli guiding this flexibility. It describes perhaps the most extreme flexibility in orb-web design yet seen. The smallest spaces were quite cramped. An adult female L. argyra in her normal resting position at the hub measured about $2.45 \mathrm{~cm}$ from tarsus I to tarsus IV, or about one-third of the diameter of the smallest containers. The ability to adjust to such small spaces is striking, because orbs in the field are never built in such small spaces.

\section{Methods}

The webs of L. argyra in the field are large, more or less horizontal orbs built in open areas where they are attached to weeds and grass in early second growth (resembling the congeneric species Leucauge mariana - Zschokke et al. 2006). Webs of adult females were photographed after coating them with cornstarch or talcum powder in captivity and in weedy undergrowth in a plantation of African oil palms in Mar. 2010 near Parrita, Puntarenas Province, Costa Rica (approx. $10 \mathrm{~m}$ ). All webs in the field were $0.5-2.0 \mathrm{~m}$ above the ground.

We experimentally manipulated the space available in which to construct an orb by confining adult female spiders in vertical cylindrical cages of different diameters formed by two sections of PVC plastic pipe $(5.8 \mathrm{~cm}$ diameter, $10 \mathrm{~cm}$ high) (windows were cut in the sides of the lower portion of the pipe), clear plastic cups $(7.5$ and $7.8 \mathrm{~cm}$ diameter at the top, $14.0 \mathrm{~cm}$ high), two sections of clear plastic soft drink bottles (11 cm diameter, $15 \mathrm{~cm}$ high), and two sections of white half-gallon plastic ice cream containers (14.8 cm diameter at the top, $16.5 \mathrm{~cm}$ high) (Fig. 1). Each cage was covered at the top with tightly stretched plastic wrapping material to which spiders almost never attached lines. The upper, internal section of each container was lined with a ring of black construction paper about $2 \mathrm{~cm}$ wide that provided footing and attachment sites for the spider; green leaves or damp paper towels were placed in the lower portion of the container to maintain suitable humidity. Spiders nearly always built their orbs near the top of the container. After the web was built, the upper portion of each container (with the web) was placed over a dark background to photograph the web. Some webs in captivity were also photographed with the spider at the hub before being powdered. Spiders in captivity built their first orb up to $7 \mathrm{~d}$ after being introduced into the container. In no case did we use more than a single web of a given female in any particular sized container; in a few cases, two different webs of the same female in two different-sized containers were used.

Measurements of lengths and areas were made from digital photographs using the program 'Image $\mathrm{J}^{\prime}$. We measured the maximum distance between points of attachment to the substrate of orbs in the field (the 'span') and the numbers of radii that ended on each frame line. The span of webs in 

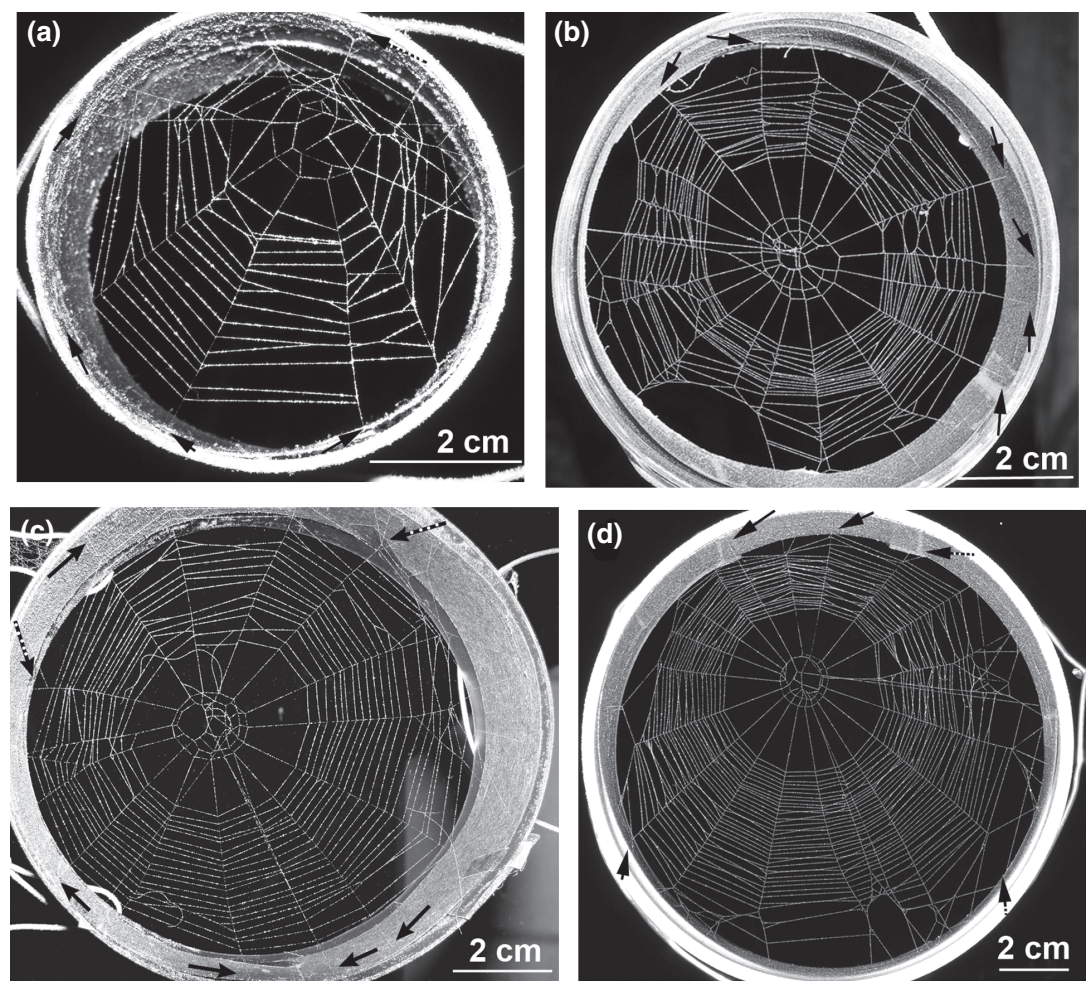

Fig. 1: Orb of mature Leucauge argyra females built in cylindrical containers of different sizes. a $-5.8 \mathrm{~cm}$ diameter; $\mathrm{b}-7.8 \mathrm{~cm}$ diameter; c $-11 \mathrm{~cm}$ diameter; $\mathrm{d}-14.8 \mathrm{~cm}$ diameter Solid arrows indicate radii attached directly to the substrate; the dotted arrow indicates a radius attached to a frame line supporting only that radius. captivity was taken to be the diameter of the container. We measured the spaces between all adjacent loops of sticky spiral on the longest radius on which clear spaces were observable and on the radius on the opposite side of the web (in portions of the web in which some sticky loops were broken or adhered to each other, we measured spaces between the same loops on adjacent radii). The hub area was the area enclosed by the outer loop of the hub spiral (Fig. 2). The free zone was the area enclosed by the inner loop of sticky spiral minus the hub area (Fig. 2). The capture area was the area enclosed by the outer loop of sticky spiral minus the area enclosed by the inner loop of sticky spiral (Fig. 2). The total area was the area enclosed by the outer loop of the sticky spiral.

We calculated the 'consistency' of the sticky spiral spacing using a modified form of the technique of Eberhard (2007). The space between two consecutive loops of sticky spiral attached to a radius ('space ${ }_{\mathrm{n}}$ ') was compared with the space immediately previous and the space immediately following on the same radius by calculating the ratio $\left(\right.$ space $\left._{\mathrm{n}}\right) /$

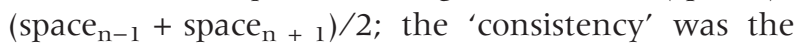
mean of these values and was measured for the longest radius and for the opposite radius. The symmetry of the web was quantified as the length of the longest radius/length of radius on opposite side of the orb (maximum = 1). The length of the entire sticky spiral was traced in a subset of the webs built in the field and in each type of container. All statistical analyses were performed using variables that were $\log _{10}$ transformed to linearize the variables and obtain normal distributions of residuals and utilized the $\mathrm{R}$ statistical Language (version 2.11: http:// cran.r-project.org). All means are followed by \pm 1 standard deviation.

Analyses of orb-web designs are facilitated by the large number of measurements that can be made on each web, but are challenging because some variables may be correlated with each other only incidentally because of the regular geometry of the orb. We confronted this possible problem by reporting a wide variety of comparisons, but focusing the discussion on variables that were potentially independent of each other, especially those traits that are determined at different stages of orb construction (see the Discussion). The order of operations in L. argyra construction is the same as is typical for other orb weavers (e.g., Eberhard 1990b; Vollrath 1992): first anchors, frames, and some radii, then the rest of the radii; then the hub, followed by the temporary spiral; and finally, starting with the outermost loop and working inward, the sticky spiral, followed by removal of the center of the hub. We used the total 


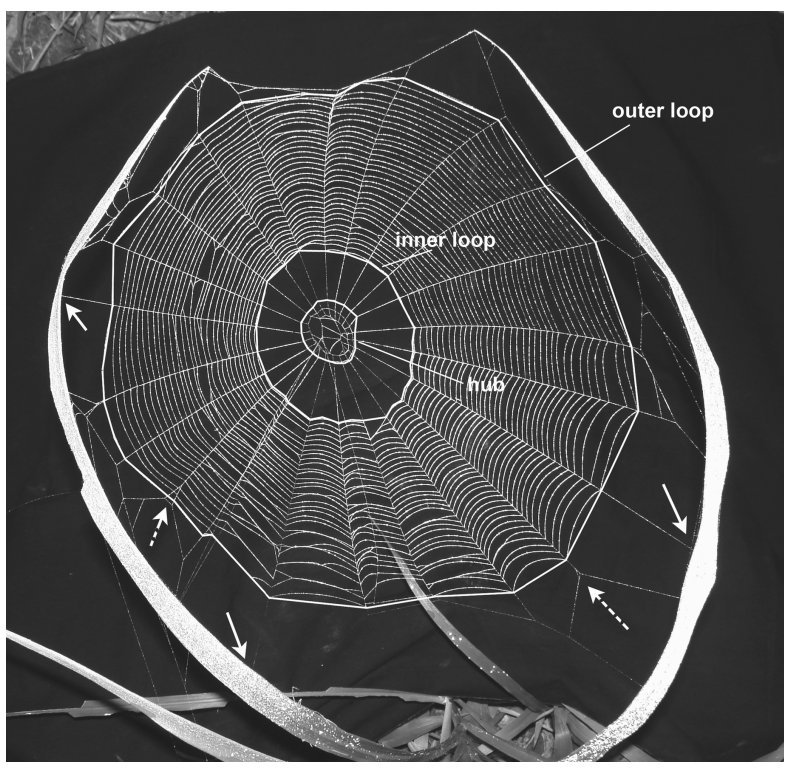

Fig. 2: Horizontal orb of a mature female Leucauge argyra that was built in an unusually small space on an isolated grass plant in the field. This web had several design features that resembled those of webs built in small containers and differed from other field webs, including radii attached directly to the substrate (solid arrows) and frame lines supporting only single radii (dotted arrows). The heavy lines indicate the areas that were measured: hub area = area enclosed by outer loop of hub; free zone area = area enclosed by inner loop - hub area; capture area = area enclosed by outer loop - free zone area; total area $=$ area included by the outer loop.

area encompassed by the outer loop of sticky spiral as an indicator of overall web size with which we compared other variables. This was because this area is a direct indicator of the functional size of the orb, and because it could be measured precisely in web photographs.

\section{Results}

Comparisons among Webs in the Field and in Different-Sized Containers

Figure 1 illustrates typical webs built in different situations, and Table 1 summarizes how their measurements varied with the space available in which to build (treatment). Field webs all spanned spaces more than $20 \mathrm{~cm}$ across $(\bar{x}=87.0 \pm 27.3 \mathrm{~cm}$, range $22-150 \mathrm{~cm})$.

The treatment explained a significant amount of the combined variation (MANOVA: $F_{56,320}=7.92$; Pillai test $=1.92 ; \mathrm{p}<0.0001)$ in 14 web features (total area, capture area, free zone area, hub area, number of radii, number of sticky spiral loops, space between sticky spiral loops on longest radius and opposite radius, consistency of spaces along both these radii, distance from the outer loop to the outer end of the radius (on a frame line or the substrate), web symmetry, proportion of radii attached directly to the substrate, and mean number of radii attached to each frame). Two webs built in $7.5 \mathrm{~cm}$ diameter containers that we checked under a dissecting microscope had small white spots on radii. These were apparently remnants of the temporary spiral, as they were very similar to the white spots left on radii when we made direct observations of temporary spiral removal during normal orb construction. Thus, even very small orbs had temporary spiral lines that were later broken, as occurs in normal orbs.

\section{Relationships with Total Web Area}

Many web variables regressed on total web area showed significant positive relationships (Fig. 3, Table 2); for those variables whose relationship is better explained with an exponential regression, we included $r^{2}$ values and the corresponding curve in Table 2 and Fig. 3 respectively. Capture area, free zone area, hub area, number of radii, number of sticky spiral loops, mean space between spiral turns on the longest and shortest radius, mean distance from outer loop to substrate or frame, sticky spiral length, and web symmetry all increased with total area. Four other variables, the consistency of sticky spiral spacing on the longest and shortest radius, the mean number of hub loops, and the asymmetry of the hub, did not correlate significantly with total area.

Comparison of slope values indicates that capture area was proportionally larger in larger webs $(b>1$, Fig. 3a), while the mean distance from the outer loop, the free zone area, and the number of sticky spiral loops increased proportionally with total area $(b=1)$; in contrast, hub area, number of radii, mean space between spiral turns, the proportion of radii attached directly to the substrate, and web asymmetry were proportionally larger in smaller webs $(b<1)$ (also Fig. 3i, Table 2). Slopes of seven regressions involving these variables were also significant when field webs were analyzed separately (slopes for distance from the outer loop and web symmetry were not significant in field webs). In all cases, unpaired t-tests of the slope for all webs did not show significant differences when compared with field webs (Fig. 3, Table 2A).

The total length of sticky spiral varied by a factor of more than ten between field webs and those in the smallest containers (Fig. 4). It had significant 
Table 1: Comparison of webs in different-sized containers with respect to 14 web design variables

\begin{tabular}{|c|c|c|c|c|c|c|c|c|}
\hline \multirow[b]{2}{*}{ Variable } & \multirow[b]{2}{*}{$\mathrm{F}$} & \multirow[b]{2}{*}{$d f$} & \multirow[b]{2}{*}{$p$} & \multicolumn{4}{|c|}{ Means in captivity } & \multirow{2}{*}{$\begin{array}{l}\text { Field means } \\
\text { Span }=87.0 \pm 27.0 \mathrm{~cm}\end{array}$} \\
\hline & & & & Span $=5.8 \mathrm{~cm}$ & Span $7.5 \mathrm{~cm}$ & Span $=11.0 \mathrm{~cm}$ & Span $=14.8 \mathrm{~cm}$ & \\
\hline Total area $(\mathrm{cm})$ & 446.9 & $4 / 80$ & $<0.00001$ & $36.82 \pm 3.50$ & $49.86 \pm 4.11$ & $78.42 \pm 6.27$ & $99.03 \pm 7.42$ & $273.13 \pm 63.51$ \\
\hline Capture area $(\mathrm{cm})$ & 327.9 & $4 / 80$ & $<0.00001$ & $13.05 \pm 5.46$ & $22.13 \pm 6.48$ & $42.13 \pm 5.20$ & $55.74 \pm 8.77$ & $204.91 \pm 77.91$ \\
\hline Free zone area $(\mathrm{cm})$ & 79.9 & $4 / 80$ & $<0.00001$ & $9.72 \pm 5.29$ & $14.17 \pm 3.77$ & $20.99 \pm 2.69$ & $27.49 \pm 3.99$ & $37.57 \pm 6.26$ \\
\hline Hub area $(\mathrm{cm})$ & 19.3 & $4 / 80$ & $<0.00001$ & $14.04 \pm 2.75$ & $13.57 \pm 2.89$ & $15.30 \pm 2.66$ & $15.64 \pm 2.39$ & $20.89 \pm 3.29$ \\
\hline Number of radii & 73.3 & $4 / 80$ & $<0.00001$ & $12.29 \pm 3.27$ & $15.13 \pm 2.77$ & $18.83 \pm 2.62$ & $18.64 \pm 2.80$ & $28.68 \pm 4.32$ \\
\hline No. sticky spiral loops & 82.9 & $4 / 80$ & $<0.00001$ & $13.36 \pm 6.15$ & $25.09 \pm 8.92$ & $40.08 \pm 9.90$ & $36.52 \pm 9.62$ & $89.64 \pm 22.27$ \\
\hline Sticky spiral space L (mm) & 29.2 & $4 / 80$ & $<0.00001$ & $1.77 \pm 0.79$ & $1.20 \pm 0.32$ & $1.57 \pm 0.63$ & $2.16 \pm 0.67$ & $3.02 \pm 0.88$ \\
\hline Sticky spiral space S (mm) & 21.2 & $4 / 80$ & $<0.00001$ & $1.57 \pm 0.81$ & $1.51 \pm 0.78$ & $1.35 \pm 0.61$ & $1.65 \pm 0.52$ & $2.75 \pm 0.75$ \\
\hline Consistency L & 1.3 & $4 / 80$ & 0.291 & $0.98 \pm 0.24$ & $1.01 \pm 0.06$ & $1.01 \pm 0.03$ & $1.02 \pm 0.05$ & $1.02 \pm 0.01$ \\
\hline Consistency S & 1.1 & $4 / 80$ & 0.346 & $0.88 \pm 0.28$ & $1.18 \pm 0.52$ & $0.99 \pm 0.11$ & $1.01 \pm 0.12$ & $1.02 \pm 0.02$ \\
\hline $\begin{array}{l}\text { Dist. from outer loop } \\
\text { (mm) }\end{array}$ & 36.2 & $4 / 91$ & $<0.00001$ & $3.80 \pm 1.61$ & $2.79 \pm 1.35$ & $3.66 \pm 1.47$ & $3.81 \pm 3.00$ & $31.92 \pm 32.98$ \\
\hline Web symmetry & 14.2 & $4 / 94$ & $<0.00001$ & $0.41 \pm 0.24$ & $0.40 \pm 0.24$ & $0.61 \pm 0.18$ & $0.75 \pm 0.15$ & $0.68 \pm 0.19$ \\
\hline $\begin{array}{l}\text { Prop. radii attached } \\
\text { to substrate }\end{array}$ & 148.7 & $4 / 94$ & $<0.00001$ & $0.69 \pm 0.21$ & $0.61 \pm 0.20$ & $0.58 \pm 0.17$ & $0.16 \pm 0.12$ & $0.01 \pm 0.03$ \\
\hline Mean radii/frame & 60.3 & $4 / 94$ & $<0.00001$ & $0.90 \pm 0.39$ & $1.29 \pm 0.36$ & $1.42 \pm 0.41$ & $1.47 \pm 0.33$ & $3.65 \pm 0.89$ \\
\hline
\end{tabular}

Means and standard deviations are included for different web sizes. $\mathrm{L}$ indicates longest radius, $\mathrm{S}$ indicates radius opposite the longest. Areas are given as square root $(\mathrm{cm})$ of the actual values.

relationships with several areas and sticky spiral measures (Fig. 4, Table 2B).

The field web that spanned the smallest space was built on a grass plant that was several meters from the next plant of similar size, so this spider may not have had other attachment sites available to build a larger web. This web (Fig. 2) had several traits seen in webs built in small containers: several radii ended on the substrate rather than on frame lines; low numbers of radii and sticky spiral loops; short distance from outer loop to the outer end of the radius; a low mean of number of radii/frame; and a high proportion of frames had only a single radius attached to them.

\section{Discussion}

The results of this study clearly support the thesis that orb-web construction behavior is typified, at least at some levels of analysis, by a high degree of flexibility (Herberstein \& Tso 2011). Housing L. argy$\mathrm{ra}$ spiders in very small cages that spanned only about $7 \%$ of the mean span of webs in nature resulted in their building orbs that differed in a suite of at least 12 different web traits (Table 1). The different aspects that changed are produced during different stages of orb construction behavior and include radius and frame construction, hub construction, construction of the first loop of sticky spiral, construction of the rest of the sticky spiral, and termination of the sticky spiral. Thus, the first conclusion to be drawn is that forcing spiders to build orbs in severely limited spaces induced them to make profound changes in orb design. These results echo changes in orb design in the araneids A. diadematus (Krink \& Vollrath 2000) and T. maudae in response to changes in the size and shape of available area. The behavioral flexibility of L. argyra offers an opportunity to understand the stimuli that guide these adjustments.

The mean span we observed in 28 field webs of mature females $(87 \pm 27 \mathrm{~cm})$ was similar to that reported in a previous study $(99.6 \pm 47.5 \mathrm{~cm}$ in 31 orbs) (Eberhard 2001). The minimum span in these studies was $22 \mathrm{~cm}$. We believe that this probably approximates the true minimum span of the webs of mature females in the field. We have seen hundreds or probably thousands of other webs of adult females of this species in the field during the course of this and other studies (Eberhard 2000, 2001; Aisenberg \& Barrantes 2011). These studies included searches for partially hidden animals, so our searches were not limited to large orbs in open spaces. The smallest containers in which we housed spiders provided only $6.7 \%$ of the mean span in the field, and $26 \%$ of the minimum span. In sum, the webs that spiders built in at least the three smallest sizes of containers that we offered were clearly unnaturally small. Presumably when a spider in the field finds herself in a space spanning only $20 \mathrm{~cm}$ or less, she simply moves to another larger site before building. 
Table 2: Relationship between different web variables. Part A: total area (A) describes the relationships between total area of the web and other 22 web features for all webs and for field webs, including the relationships between total area and the proportion of three features over the total area (each variable/total area). Part B includes the relationship between 10 web variables and sticky spiral length and Part $\mathrm{C}$ includes the relationship between total radii and other three variables. F-test for the slope $\left(\mathrm{H}_{0}: b=0\right)$, the slope value, the proportion of the variance of each dependent variable explained by total area $\left(r^{2}\right)$, and a second $r^{2}$ value is included in parentheses for those variables in which an exponential regression explained a larger proportion of the variance. T-test comparing slopes for total (bt) and field webs (bf) are included. All variables were $\log _{10}$-transformed. $\mathrm{L}$ indicates longest radius: $\mathrm{S}$ indicates radius opposite the longest. Areas are given as the square root of the actual values

\begin{tabular}{|c|c|c|c|c|c|c|c|c|c|c|c|c|}
\hline \multirow[b]{2}{*}{ Variable } & \multicolumn{5}{|l|}{ All webs } & \multicolumn{5}{|c|}{ Field webs } & \multicolumn{2}{|c|}{$\begin{array}{l}\text { Test between } \\
\text { slopes }\end{array}$} \\
\hline & $F$ & $\mathrm{df}$ & $\mathrm{p}$ & Slope $(b)$ & $r^{2}$ & $F$ & $d f$ & $\mathrm{p}$ & Slope (b) & $r^{2}$ & $t_{(\mathrm{bt}-\mathrm{bf})}$ & $\mathrm{p}_{(\mathrm{bt}-\mathrm{bf})}$ \\
\hline \multicolumn{13}{|l|}{ A - total area (independent variable) } \\
\hline Capture area & 2235.0 & $1 / 105$ & $<0.00001$ & 1.39 & 0.96 & 1753.0 & $1 / 25$ & $<0.00001$ & 1.16 & 0.99 & 0.98 & 0.329 \\
\hline Free zone & 200.1 & $1 / 105$ & $<0.00001$ & 0.68 & 0.66 & 17.3 & $1 / 25$ & 0.001 & 0.48 & 0.41 & 0.51 & 0.613 \\
\hline Hub area & 89.2 & $1 / 105$ & $<0.00001$ & 0.23 & 0.46 & 13.5 & $1 / 25$ & 0.001 & 0.40 & 0.35 & 0.46 & 0.644 \\
\hline Number of radii & 291.7 & $1 / 99$ & $<0.00001$ & 0.40 & 0.75 & 9.0 & $1 / 25$ & 0.006 & 0.32 & 0.27 & 0.23 & 0.819 \\
\hline No. sticky spiral loops & 409.1 & $1 / 98$ & $<0.00001$ & 0.89 & 0.89 & 9.8 & $1 / 25$ & 0.004 & 0.51 & 0.28 & 0.84 & 0.404 \\
\hline Mean no. hub loops & 2.25 & $1 / 102$ & 0.137 & 0.30 & 0.02 & 0.03 & $1 / 24$ & 0.863 & -0.24 & 0.00 & & \\
\hline Sticky spiral space L & 82.0 & $1 / 98$ & $<0.00001$ & 0.42 & $0.46(0.47)$ & 8.5 & $1 / 25$ & 0.007 & 0.57 & 0.25 & 0.30 & 0.764 \\
\hline Sticky spiral space S & 47.1 & $1 / 94$ & $<0.00001$ & 0.37 & $0.33(0.39)$ & 5.7 & $1 / 25$ & 0.024 & 0.49 & 0.18 & 0.24 & 0.813 \\
\hline Consistency L & 2.4 & $1 / 96$ & 0.123 & 0.03 & 0.02 & 0.1 & $1 / 25$ & 0.785 & -0.01 & 0.01 & & \\
\hline Dist. from outer loop & 71.3 & $1 / 94$ & $<0.00001$ & 1.04 & $0.43(0.50)$ & 0.1 & $1 / 23$ & 0.807 & -0.21 & 0.00 & 1.27 & 0.207 \\
\hline Dist. longest radius & 1010.0 & $1 / 70$ & $<0.00001$ & 0.91 & 0.93 & 124.1 & $1 / 11$ & $<0.00001$ & 0.89 & 0.92 & 0.07 & 0.945 \\
\hline Dist. shortest radius & 540.2 & $1 / 70$ & $<0.00001$ & 1.05 & 0.88 & 21.9 & $1 / 11$ & 0.001 & 1.04 & $0.66(0.88)$ & 0.03 & 0.980 \\
\hline Web symmetry & 45.7 & $1 / 97$ & $<0.00001$ & 0.44 & 0.32 & 0.5 & $1 / 25$ & 0.506 & 0.23 & 0.02 & 0.33 & 0.744 \\
\hline Hub symmetry & 1.8 & $1 / 97$ & 0.179 & -0.02 & 0.02 & 0.6 & $1 / 24$ & 0.445 & -0.07 & 0.02 & & \\
\hline Prop. radii attached to substrate & 294.3 & $1 / 96$ & $<0.00001$ & -1.00 & 0.75 & 0.9 & $1 / 24$ & 0.833 & -0.18 & 0.03 & 1.64 & 0.104 \\
\hline Prop. frame $w$. single radius & 45.1 & $1 / 92$ & $<0.00001$ & -0.46 & 0.33 & 2.1 & $1 / 22$ & 0.164 & -0.31 & 0.09 & 0.28 & 0.779 \\
\hline Mean radii/frame & 234.5 & $1 / 92$ & $<0.00001$ & 0.43 & $0.72(0.74)$ & 2.5 & $1 / 22$ & 0.763 & 0.29 & 0.01 & 0.30 & 0.763 \\
\hline Number of frame lines & 28.4 & $1 / 92$ & $<0.00001$ & 0.41 & 0.24 & 0.1 & $1 / 22$ & 0.831 & -0.05 & 0.00 & 0.81 & 0.416 \\
\hline Prop. Capture area/total area & 195.4 & $1 / 105$ & $<0.00001$ & 0.27 & 0.65 & 66.4 & $1 / 25$ & $<0.00001$ & 0.09 & 0.73 & 1.06 & 0.289 \\
\hline Prop. Free zone area/total area & 0.77 & $1 / 105$ & 0.372 & 0.03 & 0.01 & 2.3 & $1 / 25$ & 0.140 & -0.07 & 0.08 & & \\
\hline Prop. Hub area/total area & 171.7 & $1 / 105$ & $<0.00001$ & -0.19 & $0.62(0.66)$ & 1.4 & $1 / 25$ & 0.243 & -0.06 & 0.05 & 0.55 & 0.584 \\
\hline \multicolumn{13}{|c|}{ B - sticky spiral length (dependent variable) } \\
\hline Free zone area & 38.5 & $1 / 23$ & $<0.00001$ & 1.67 & 0.63 & 0.02 & $1 / 3$ & 0.895 & -0.27 & 0.01 & 1.33 & 0.196 \\
\hline Hub area & 16.6 & $1 / 23$ & 0.0005 & 3.89 & 0.42 & 2.1 & $1 / 3$ & 0.243 & -4.77 & 0.41 & 4.20 & 0.000 \\
\hline Number of radii & 64.6 & $1 / 23$ & $<0.00001$ & 3.09 & 0.74 & 1.9 & $1 / 3$ & 0.261 & 1.60 & 0.39 & 1.20 & 0.240 \\
\hline Number sticky spiral loops & 347.0 & $1 / 23$ & $<0.00001$ & 1.83 & 0.94 & 30.9 & $1 / 3$ & 0.011 & 1.24 & 0.91 & 1.02 & 0.317 \\
\hline Sticky spiral space L & 20.5 & $1 / 23$ & 0.0001 & 2.13 & 0.47 & 3.3 & $1 / 3$ & 0.167 & -2.03 & 0.52 & 3.30 & 0.003 \\
\hline Sticky spiral space S & 5.6 & $1 / 22$ & 0.027 & 1.30 & $0.20(0.23)$ & 0.2 & $1 / 3$ & 0.660 & -0.66 & 0.07 & 1.41 & 0.167 \\
\hline Consistency L & 2.7 & $1 / 23$ & 0.111 & -5.31 & $0.11(0.47)$ & 1.0 & $1 / 3$ & 0.382 & -23.00 & 0.26 & & \\
\hline Consistency S & 4.3 & $1 / 19$ & 0.052 & 2.79 & 0.18 & 2.4 & $1 / 3$ & 0.222 & -13.58 & 0.44 & & \\
\hline \multicolumn{13}{|l|}{ C - total radii (independent variable) } \\
\hline Prop. radii attached to substrate & 108.5 & $1 / 92$ & $<0.00001$ & -1.87 & 0.54 & 2.7 & $1 / 22$ & 0.114 & -0.45 & 0.11 & 2.09 & 0.038 \\
\hline Prop. frames w. single radius & 20.9 & $1 / 92$ & $<0.0001$ & -0.52 & 0.18 & 2.7 & $1 / 22$ & 0.114 & -0.45 & 0.11 & 0.43 & 0.670 \\
\hline Mean radii/frame & 114.5 & $1 / 92$ & $<0.00001$ & 2.02 & 0.80 & 0.7 & $1 / 22$ & 0.794 & 0.07 & 0.05 & 1.30 & 0.198 \\
\hline
\end{tabular}

Several of the design adjustments in the webs in very small spaces appear to represent 'continuations' of similar adjustments that the spiders make to less severe space constraints in nature. They thus help elucidate cues used during orb construction. This continuation interpretation is supported by similari- ties between the slopes of the relationships of some variables to total area in field webs and the relationships of the same variables to total area when webs in experimental containers were added (Fig. 3; comparisons of slopes in Table 2). These 'continuations' included adjustments in the number of radii 

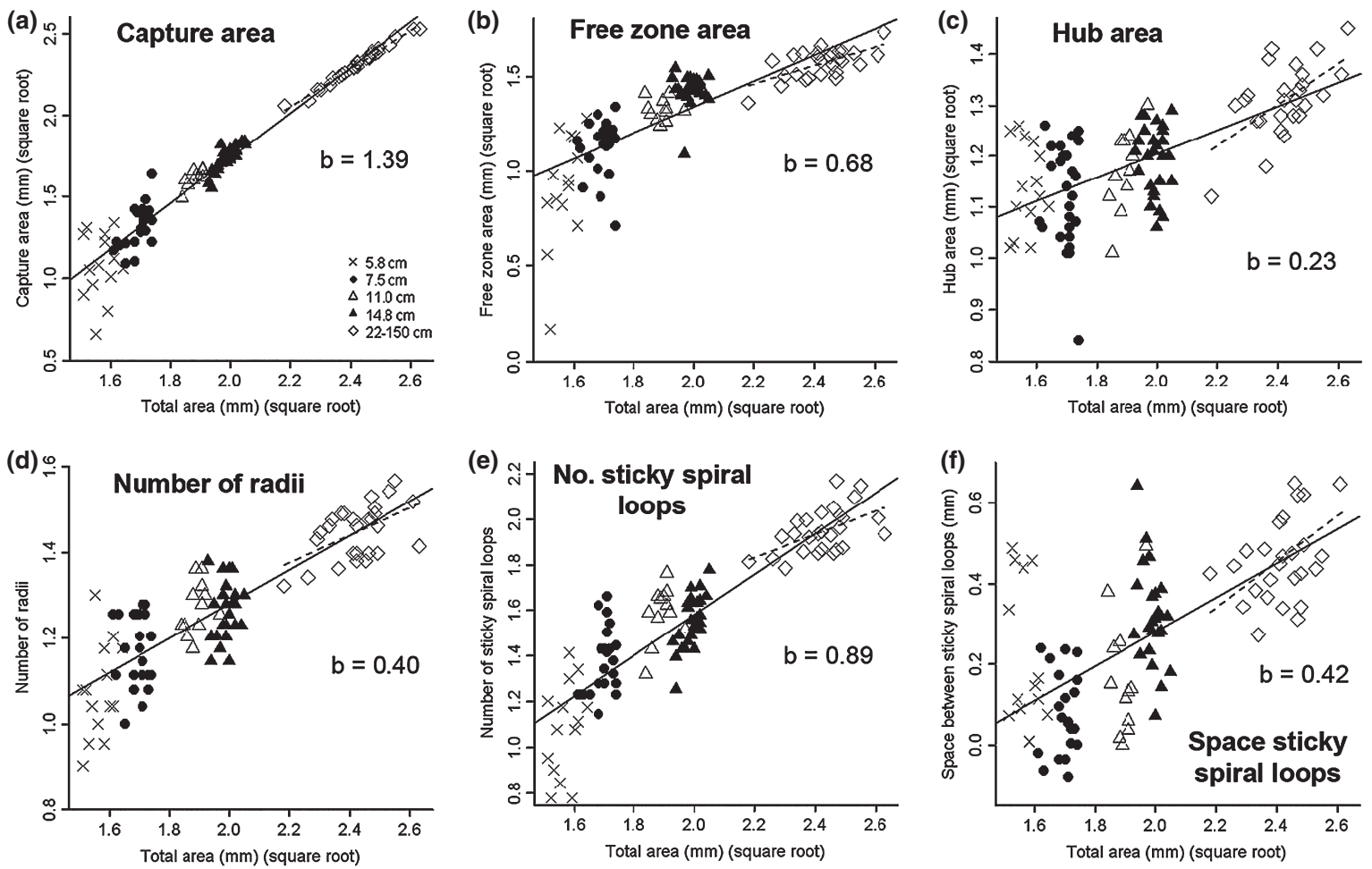

(g)

(h)
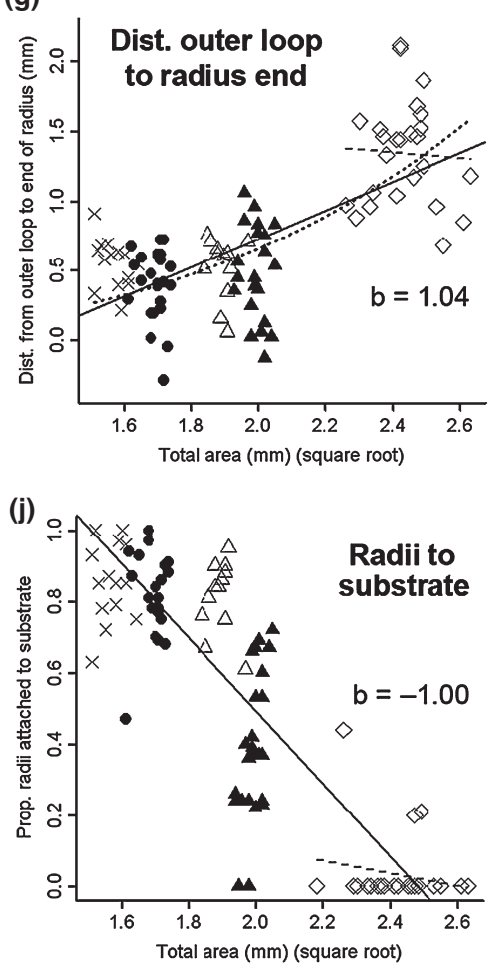

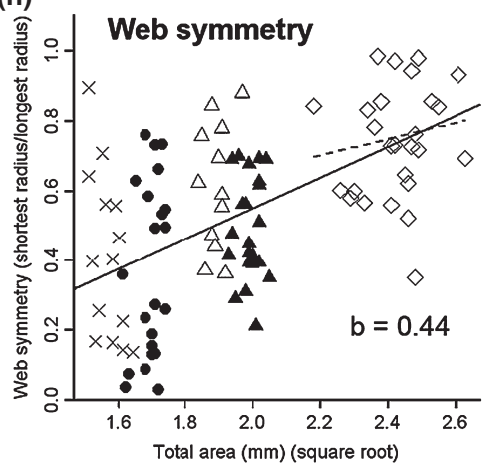

(k)

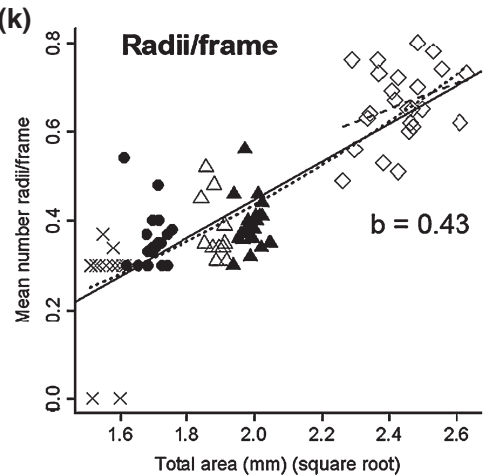

(i)
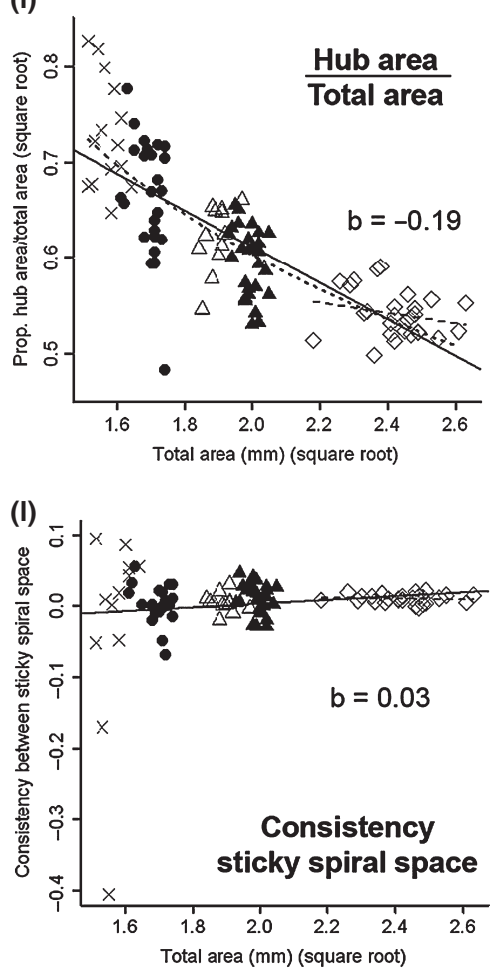

Fig. 3: Relationships of total area to each of the other traits in webs built in the field and in small containers of different sizes. The continuous line corresponds to the total area regressed against each of the other web traits for all webs and the dashed line corresponds to the total area regressed against each of the other web traits for field webs. A dotted curve is included when an exponential regression explain better the relationship of total area with the correspondent web trait. The slope value for all webs is included in each case. All variables were log ${ }_{10}$-transformed. 
Fig. 4: Relations of the total length of sticky spiral to several web variables in orbs built in the field and in containers of different sizes. The continuous line corresponds to the relationship of total length with each of the web traits for all webs, and the dashed line for field webs. The slope value for all webs is included in each case. All variables were $\log _{10}$-transformed.
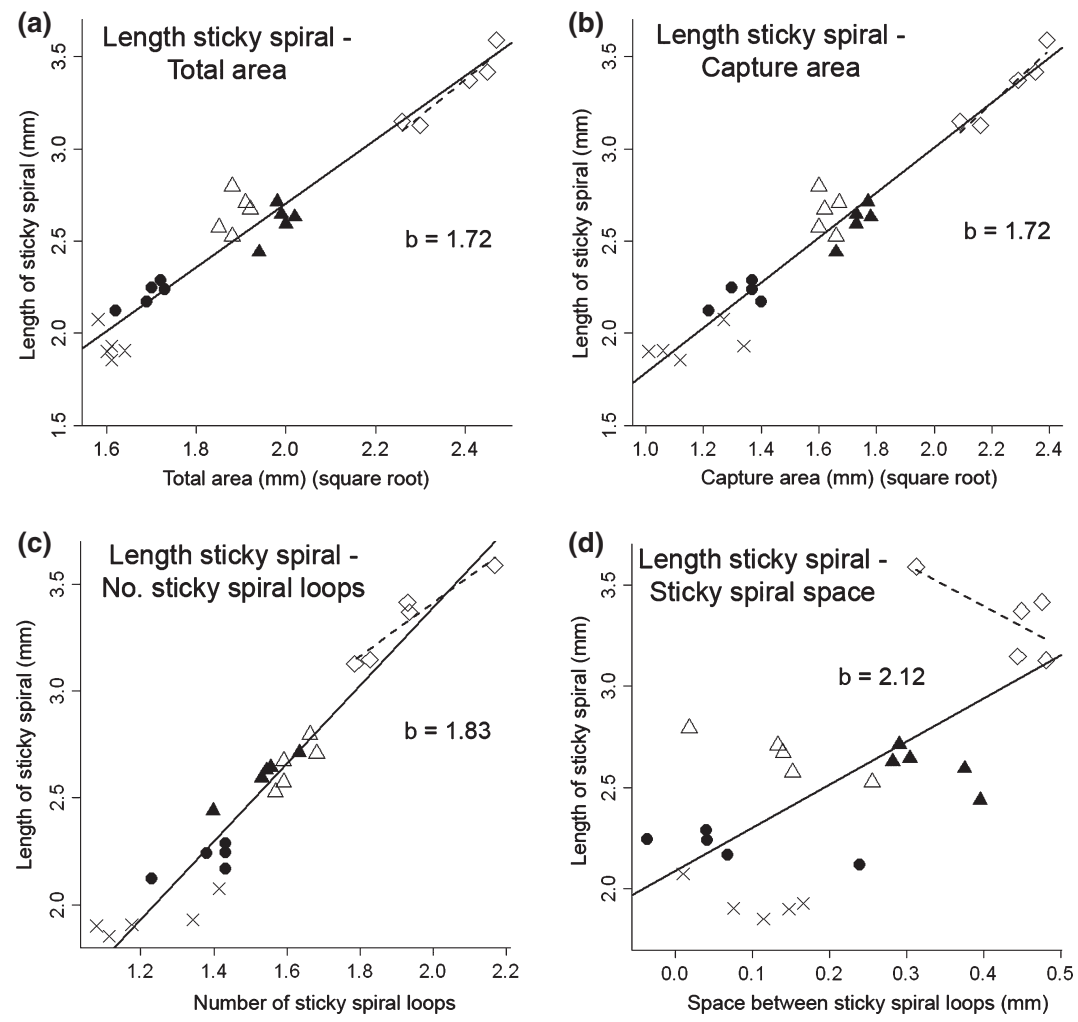

(Fig. 3d), the number of sticky spiral loops (Fig. 3e), the spaces between sticky spiral loops (Fig. 3f), the capture area (Fig. 3a), the hub area (Fig. 3c), the free zone area (Fig. 3b), and the proportion of the total area that is dedicated to the hub area (Fig. 3i). In accord with this interpretation, the design of the smallest field web (Fig. 2) showed several alterations that were similar to but less extreme than those seen in webs in small containers.

Contrary to the continuation hypothesis, some other adjustments in web design in small containers were not clear continuations of trends in field webs; the field webs showed no significant trends in these traits (Table 2). These adjustments included reduced distance from the outer sticky spiral loop to the end of the radius (Fig. 3g), decreased web symmetry (Fig. 3h), and four different variables associated with frame construction, including increased proportion of radii attached directly to the substrate (Fig. 3j), and decreased mean number of radii attached to given frame lines (Fig. 3k). 'Small space traits' (radii attached directly to the substrate, frames with fewer radii) did occur occasionally, however, in field webs, and frames with fewer radii were associated there with shorter radii. Web symmetry varied substantially in the field and included values nearly as low as the means in the smallest containers.
Summarizing in qualitative terms, this set of 'noncontinuation' traits that were accentuated in webs in small spaces did not represent any new design features that were never seen in field webs. In this more limited, qualitative sense, the designs of webs built in small spaces were also 'continuous' with the designs in field webs.

The substantial flexibility documented here and in other experiments with orb weavers (LeGuelte 1966; Krink \& Vollrath 2000; Harmer \& Herberstein 2009) demonstrates the importance of habitat choice in determining many aspects of orb design. In other words, some differences between species in their orb designs may stem from differences in the sites they choose in which to build their orbs, rather than differences in their construction behavior per se. These results reinforce previous conclusions (e.g., Eberhard 1990a; Harmer \& Herberstein 2009) that multiple aspects of orb design (although not all - see Kuntner et al. 2008) may be of limited usefulness as characters in studies of phylogeny.

Some of the design adjustments to being confined in small cages reported here, such as reduced spaces between sticky spiral loops, also occur in A. diadematus (Krink \& Vollrath 2000) and in the distantly related uloborid Zosis geniculata (Eberhard $\delta$ Barrantes in prep.). The changes in L. argyra 
webs also resembled changes by $N$. clavipes confined in small spaces (Hesselberg 2010), in that the hub and free zone were relatively large compared with the rest of the orb; they differed from $N$. clavipes, in that the asymmetry of smaller orbs was increased rather than reduced. Some of traits used by L. argyra to adjust to small spaces, in particular, reduction in the number of radii as well as reduction and omission of frame lines, also occur in nature, in the webs of the anapid Anapisona simoni, which are built deep in leaf litter (Eberhard 2007). This suggests that the web design of this anapid may have evolved to allow the spiders to use cramped sites.

\section{Independence of Variables and their Biological 'Reality'}

How many of the variables in Tables 2 and 3 reflect different design characteristics that are under independent control in the spider? Or, to rephrase the question, how many types of decisions by the spider were altered independently when they built webs in restricted spaces? We cannot give a precise numerical answer, but can make a conservative estimate. In the first place, a few of 12 variables that changed (Table 1) and 28 altered relations between variables that were altered (Table 2) were physically imposed by the sizes of the spaces and cannot be properly considered because of choices of the spiders. For instance, capture area and radius length were necessarily reduced in smaller containers.

Secondly, it seems highly unlikely that all of the variables in Tables 1 and 2 reflect independent decision processes by the spiders. For instance, we do not suppose that the number of loops of sticky spiral resulted from any sort of decision by the spider regarding numbers; more likely the number of loops resulted from a combination of decisions that included: (1) how close to the end of the radius to attach the outer loop of sticky spiral; (2) how far apart to space succeeding loops; and (3) when to terminate sticky spiral construction.

\begin{tabular}{|c|c|c|c|}
\hline & Webs in smaller spaces & $\begin{array}{l}\text { Probable } \\
\text { independent } \\
\text { group (see text) }\end{array}$ & $\begin{array}{l}\text { Continuous } \\
\text { field trend in } \\
\text { smaller webs }\end{array}$ \\
\hline \multicolumn{4}{|l|}{ Relative areas } \\
\hline Capture area* & Smaller* & & \\
\hline Hub area & Smaller (not proportional) & C & Yes \\
\hline Free zone area & Smaller (not proportional) & $\mathrm{g}$ & Yes \\
\hline Symmetry & Smaller & $d$ & No \\
\hline \multicolumn{4}{|l|}{ Radii, frames, anchor lines } \\
\hline Number of radii & Smaller & $\mathrm{b}$ & Yes \\
\hline Length of radii* & Smaller* & & Yes?* \\
\hline Number of frame lines & Smaller & a & Yes $^{5}$ \\
\hline $\begin{array}{l}\text { Proportion of radii } \\
\text { attached directly to substrate }\end{array}$ & Greater & $a$ & No \\
\hline $\begin{array}{l}\text { Proportion of frame } \\
\text { lines with only a single radius }\end{array}$ & Greater & a & No \\
\hline Number radii/frame line & Smaller & a & $Y_{e s}{ }^{a}$ \\
\hline $\begin{array}{l}\text { Proportion of radii that } \\
\text { end on a single frame lines }\end{array}$ & Larger & a & No \\
\hline \multicolumn{4}{|l|}{ Sticky spiral } \\
\hline $\begin{array}{l}\text { Distance from outer loop of } \\
\text { sticky spiral to end of radius }\end{array}$ & Smaller & $\mathrm{e}$ & No \\
\hline Number loops of sticky spiral & Smaller & $f$ & Yes \\
\hline $\begin{array}{l}\text { Space between loops of } \\
\text { sticky spiral }\end{array}$ & Smaller & $f$ & Yes \\
\hline $\begin{array}{l}\text { Distance from outer loop of hub } \\
\text { to inner loop of sticky spiral } \\
\text { (free zone) }\end{array}$ & Smaller & $g$ & Yes \\
\hline Consistency of sticky spiral spaces & No change & & No \\
\hline \multicolumn{4}{|l|}{ Hub } \\
\hline Number loops hub spiral & No change & & Yes \\
\hline Space between hub loops & Smaller & c & ??* \\
\hline
\end{tabular}

Table 3: Summary of the differences in design features of orb webs built by adult female Leucauge argyra spiders in the field and in smaller containers, and their likely degree of independence. The differences (e.g., shorter radii, smaller capture area) that can be directly attributed to simple physical limitations imposed by smaller available spaces are marked with '*'. Other differences in design are not imposed directly by the smaller spaces (e.g., smaller spaces between loops of sticky spiral, lower numbers of radii, greater fraction of radii attached directly to the substrate). Variables determined by possibly independent decisions are labeled with different letters, in the order in which they occur during orb construction (see Discussion)

${ }^{a}$ Only a weak trend in field webs. ? indicates unavailable information. 
It is important to note that the question of biological independence is not necessarily the same as the question of statistical independence. For instance, the effect on the number of loops resulting from the decision how far from the end of the radius to place the first loop will be influenced by the length of the radius, and the radius length is tightly correlated with the number of sticky loops $(r=0.87, \mathrm{df}=70$, $\mathrm{p}<0.00001)$. But radius length is determined at a much earlier stage of orb construction (radius and frame construction) than is the placement of the first loop and the two kinds of decision are influenced by different stimuli; the attachment site of the first loop is influenced by the site of the outer loop of temporary spiral (Eberhard 1972, W. G. Eberhard, in press), a line that is not even present when radii are constructed. Despite a possible statistical correlation, these two aspects of design are properly considered to result from separate design decisions.

We see two a priori, common sense criteria to distinguish biologically independent web design decisions: that they occur separately in time and that they are influenced by different cues. Using only these criteria, however, leaves open the possibility that there is a hierarchy of decisions in the spider, such that decisions that would be considered separate by these two criteria might nevertheless be linked because they are two direct, lower-level consequences of a single higher-level decision. This leads us to include a third common sense criterion - the physical feasibility of independence in the lower-level decisions. For instance, it is not physically possible for the number of radii to be independent of the mean angle between adjacent radii when the spider builds new radii during radius construction. On the other hand, it is entirely feasible for the spider to build a long radius, and then to either attach the first loop of sticky spiral near its outer end, or to attach it far from its end. This independence criterion emphasizes the possibility that there is variation in one decision even after the other, previous decision has been made. It emphasizes the possibility that natural selection can act separately on the two decisions and that they can evolve independently. In some sense, these behavioral questions are related to discussions of evolutionary 'constraints', which are more often discussed in the context of morphological evolution (Gould $\delta$ Lewontin 1979; Müller \& Wagner 1991; West-Eberhard 2006).

Using these three criteria conservatively, we believe that our experimental confinement of spiders to very small containers resulted in the spiders changing at least seven different kinds of design decisions (letters in Table 3): (a) whether or not frame lines would be built as part of radius construction and how long the frame lines would be; (b) angles between adjacent radii during radius construction; (c) spaces between hub loops (built after radii were finished); (d) degree of asymmetry in placement of the hub; (e) distance between attachments of the outer loop of sticky spiral and the outer ends of the radii; (f) spaces between sticky spiral loops; and (g) distance from the hub at which sticky spiral construction was terminated. This is a conservative list, because possibly more than one decision was involved in producing the changes in the five different variables that we have cataloged as resulting from decision (a) (Table 3).

Our proposal that these different design decisions are to some extent independent of each other in L. argyra is in accord with several other types of data. Japyassu \& Ades (1998) showed that differences in the timing of ontogenetic changes in different web traits suggest the existence of semi-independent modules controlling orb construction in the nephilid Nephilengys cruentata and reviewed evidence of similar independence in the ontogenetic changes in other species. Different species of parasitoid ichneumonid wasps elicit quite different arrays of changes in the orbs of their host spiders, in some cases by highly specific stimulation and repression of particular details of orb construction (e.g., elicit one subroutine of frame construction and repress others) (Nielsen 1923; Gonzaga \& Sobczak 2007; Gonzaga et al. 2010; Eberhard 2001, 2010; Matsumoto \& Konishi 2007). In addition, the webs of related species of orb weavers show different mixes of similarities and differences (e.g., Coddington 1986; Eberhard 1986; Lubin 1986). As noted by Japyassu \& Ades (1998), uncoupling between behavioral routines enhances the evolutionary plasticity of orb weavers.

It is important to note that subprograms of behavior that are independent may nevertheless be linked at a higher level of analysis. For instance, as argued by Krink \& Vollrath (2000), stimuli perceived and analyzed by the spider during preliminary exploration behavior may alter several different web construction algorithms. In general, flexibility results from a hierarchy of decisions in both behavior and morphology (West-Eberhard 2006).

\section{Acknowledgements}

Anita Aisenberg generously shared her key discovery that female L. argyra will build orbs in small plastic cups; Jairo Moya made useful suggestions regarding 
the designs of containers and helped construct them. Sr. Pedro Gaspar allowed us to work in his oil palm plantation. The Smithsonian Tropical Research Institute and the Vicerrectoría de Investigación of the Universidad de Costa Rica provided financial support.

\section{Literature Cited}

Ades, C. 1986: A construcão da teia geométrica como programa comportamental. Ciencia Cult. 38, 760-775.

Aisenberg, A. \& Barrantes, G. 2011: Sexual behavior, cannibalism, and mating plugs as sticky traps in the orb weaver spider Leucauge argyra. Naturwissenschaften 98, 605-613.

Blamires, S. J., Thompson, M. B. \& Hochuli, D. F. 2007: Habitat selection and web plasticity by the orb spider Argiope keyserlini (Argiopidae): do they compromise foraging success for predator avoidance? Austral Ecol. 32, 551-563.

Cangialosi, K. R. \& Uetz, G. W. 1987: Spacing in colonial spiders: effects of environment and experience. Ethology 76, 236-246.

Coddington, J. A. 1986: The monophyletic origin of the orb web. In: Spiders Webs Behavior and Evolution (Shear, W. A., ed). Stanford Univ. Press, Palo Alto, pp. 319-363.

Eberhard, W. G. 1972: The web of Uloborus diversus (Araneae: Uloboridae). J. Zool. 166, 417-465.

Eberhard, W. G. 1986: Effects of orb-web geometry on prey interception and retention. In: Spiders Webs Behavior and Evolution (Shear, W. A., ed). Stanford Univ. Press, Palo Alto, pp. 70-100.

Eberhard, W. G. 1988a: Memory of distances and directions moved as cues during temporary spiral construction in the spider Leucauge mariana (Araneae: Araneidae). J. Ins. Behav. 1, 51-66.

Eberhard, W. G. 1988b: Behavioral flexibility in orb web construction: effects of supplies in different silk glands and spider size and weight. J. Arachnol. 16, 295-302.

Eberhard, W. G. 1990a: Function and phylogeny of spider webs. Ann. Rev. Ecol. Syst. 21, 341-372.

Eberhard, W. G. 1990b: Early stages of orb construction by Philoponella, Leucauge, and Nephila spiders (Araneae: Uloboridae and Araneidae). J. Arachnol. 18, 205-234. Eberhard, W. G. 2000: The natural history and behavior of Hymenoepimecis argyraphaga (Hymenoptera: Ichneumonidae) a parasitoid of Plesiometa argyra (Araneae: Tetragnathidae). J. Hymenop. Res. 9, 220-240.

Eberhard, W. G. 2001: Under the influence: webs and building behavior of Plesiometa argyra (Araneae, Tetragnathidae) when parasitized by Hymenoepimecis argyraphaga (Hymenoptera, Ichneumonidae). J. Aracnol. 29, 354-366.
Eberhard, W. G. 2007: Miniaturized orb-weaving spiders: behavioural precision is not limited by small size. Proc. R. Soc. Lond. B 274, 2203-2209.

Eberhard, W. G. 2010: Recovery of spiders from the effects of parasitic wasps: implications for fine-tuned mechanisms of manipulation. Anim. Behav. 79, 375-383.

Eberhard, W. G. (in press): Cues guiding placement of the first loop of sticky spiral in orbs of Micrathena duodecimspinosa (Araneidae) and Leucauge mariana (Tetragnathidae). Bull. Brit. Arachnol. Soc., in press.

Gillespie, R. 1987: The role of prey availability in aggregative behavior of the orb weaving spider, Tetratnatha elongata. Anim. Behav. 35, 675-681.

Gonzaga, M. \& Sobczak, J. F. 2007: Parasite-induced mortality of Araneus omnicolor (Araneae, Araneidae) by Hymenoepimecis sp. (Hymenoptera, Ichneumonidae) in southeastern Brazil. Naturwissenschaften 94, $223-227$.

Gonzaga, M., Sobczak, J. F., Penteado-Dias, A. M. \& Eberhard, W. G. 2010: Modification of Nephila clavipes (Araneae, Nephilidae) by the parasitoids Hymenoepimecis bicolor and H. robertsae (Hymenoptera, Ichneumonidae). Ethol. Ecol. Evol. 22, 151-165.

Gould, S. J. \& Lewontin, R. 1979: The spandrels of San Marco and the Panglossian paradigm: a critique of the adaptationist programme. Proc. R. Soc. Lond. B 205, 581-598.

Harmer, A. M. T. \& Herberstein, M. E. 2009: Taking it to extremes: what drives extreme web elongation in Australian ladder web spider (Araneidae: Telaprocera maudae)? Anim. Behav. 78, 499-504.

Heiling, A. M. \& Herberstein, M. E. 2000: Interpretations of orb-web variability: a review of past and current ideas. Ecológia (Bratislava) 19(Suppl. 3), 97-106.

Herberstein, M. E. \& Heiling, A. M. 1999: Asymmetry in spider orb webs: a result of physical restraints? Anim. Behav. 58, 1241-1246.

Herberstein, M. E. \& Tso, I.-M. 2011: Spider webs: evolution, diversity and plasticity. In: Spider Behavior, Flexibility and Plasticity (Herberstein, M. E., ed). Cambridge Univ. Press, New York, NY, pp. 57-98.

Herberstein, M. E., Craig, C. L. \& Elgar, M. A. 2000: Foraging strategies and feeding regimes: web and decoration investment in Argiope keyserlingi Karsch (Araneae: Araneidae). Evol. Ecol. Res. 2, 69-80.

Hesselberg, T. 2010: Ontogenetic changes in web design in two orb weavers. Ethology 116, 535-545.

Higgins, L. 1990: Variation in foraging investment during the intermolt interval and before egg-laying in the spider Nephila clavipes. J. Ins. Behav. 3, 773-783.

Higgins, L. 1992: Developmental changes in barrier web structure under different levels of predation risk in 
Nephila clavipes (Araneae: Tetragnathidae). J. Ins.

Behav. 5, 635-655.

Higgins, L. \& Buskirk, R. E. 1992: Foraging strategies and diet of the large orb-weaving spider Nephila clavipes.

Anim. Behav. 44, 485-499.

Hingston, R. W. G. 1920: A Naturalist in the Himalaya. Small, Maynard and Company, Boston.

Hingston, R. W. G. 1922: The snare of the giant wood spider (Nephila maculata). J. Bombay Nat. Hist. Soc. 28, 642-655.

Japyassu, H. F. \& Ades, C. 1998: From complete orb to semi-orb webs: developmental transistions in web of Nephilengys cruentata (Araneae: Tetragnathidae). Behaviour 135, 931-956.

Krink, T. \& Vollrath, F. 2000: Optimal area use in orb webs of the spider Araneus diadematus. Naturwissenschaften 87, 90-93.

Kuntner, M., Coddington, J. A. \& Hormiga, G. 2008: Phylogeny of extant nephilid orb-weaving spiders (Araneae, Nephilidae): testing morphology and ethological homologies. Cladistics 24, 147-217.

Leborgne, R. \& Pasquet, A. 1987: Influences of aggregative behaviour on space occupation in the spider Zygiella $x$-notata (Clerck). Behav. Ecol. Sociobiol. 20, 203-208.

LeGuelte, L. 1966: Structure de la toile de Zygiella x-notata Cl. (Araignées, Argiopidae) et facteurs que régissent le comportement de l'Araignée pendant la construction de la toile. Thèse, Publ. Univ. Nancy, Nancy.

Lubin, Y. D. 1986: Web building and prey capture in the Uloboridae. In: Spiders Webs Behavior and Evolution (Shear, W. A., ed). Stanford Univ. Press, Palo Alto, pp. 132-171.
Matsumoto, R. \& Konishi, K. 2007: Life histories of two ichneumonid parasitoids of Cyclosa octotuberculata (Araneae): Reclinervellus tuberculatus (Uchida) and its new sympatric congener (Hymenoptera: Ichneumonidae: Pimplinae). Ent. Sci. 10, 267-278.

Müller, G. B. \& Wagner, G. P. 1991: Novelty in evolution: restructuring the concept. Ann. Rev. Ecol. Syst. 22, 229-256.

Nielsen, E. T. 1923: Contributions to the life history of the pimpline spider parasites (Polysphincta, Zaglyptus, Tomatobia). Ent. Meddel. 14, 137-205.

Reed, C. F., Witt, P. N., Scarboro, M. \& Peakall, D. B. 1970: Experience and the orb web. Psychobiol. 3, 251-265.

Sandoval, C. P. 1994: Plasticity in web design in the spider Parawixia bistriata: a response to variable prey type. Funct. Ecol. 8, 701-707.

Sherman, P. M. 1994: The orb-web: an energetic and behavioral estimator of a spider's dynamic foraging and reproductive strategies. Anim. Behav. 48, 19-34.

Vollrath, F. 1992: Analysis and interpretation of orb spider exploration and web building behavior. Adv. Stud. Behav. 21, 147-199.

West-Eberhard, M. J. 2006: Developmental Plasticity and Evolution. Oxford Univ. Press, New York, NY.

Witt, P. N. 1965: Do we live in the best of all possible worlds? Spider webs suggest an answer. Persp. Biol. Med. 8, 475-487.

Witt, P. N., Reed, C. \& Peakall, D. B. 1968: A Spider's Web. Springer Verlag, New York, NY.

Zschokke, S., Hénaut, Y., Benjamin, S. P. \& GarciaBallinas, J. A. 2006: Prey-capture strategies in sympatric web-building spiders. Can. J. Zool. 84, 964-973. 